\title{
CURSO DE VIDA, ADOLESCENTES E CRIMINALIDADE: UMA LEITURA A PARTIR DO PIA
}

\author{
CURSO DE VIDA, ADOLESCENTES Y CRIMINALIDAD: \\ UNA LECTURA A PARTIR DEL PIA

\section{LIFE COURSE, ADOLESCENTS AND CRIMINALITY: A STUDY BASED ON PIA}

\author{
Lucas Caetano Pereira Oliveira ${ }^{1}$, Jacqueline de Oliveira Moreira ${ }^{2}$, \\ Bráulio Figueiredo Alves da Silva ${ }^{1}$, Frederico Couto Marinho, \\ Juliana Marcondes Pedrosa de Souza ${ }^{4}$ \\ ${ }^{1}$ Universidade Federal de Minas Gerais, Belo Horizonte/MG, Brasil \\ ${ }^{2}$ Pontifícia Universidade Católica de Minas Gerais, Belo Horizonte/MG, Brasil
}

${ }^{3}$ Universidade Federal de Minas Gerais, Centro de Estudos de Criminalidade e Segurança Pública (CRISP), Belo Horizonte/MG, Brasil

${ }^{4}$ Centro Universitário Metodista Izabela Hendrix, Belo Horizonte/MG, Brasil

RESUMO: Este texto pretende pensar as articulações entre o curso de vida e, principalmente, a trajetória infracional de adolescentes que cumprem medida socioeducativa de Internação e Semiliberdade por tráfico de drogas em uma cidade mineira. Orientado, no âmbito da Sociologia, pela criminologia de curso de vida e, no âmbito da Psicologia, pela escuta da singularidade da vida adolescente, este trabalho apresenta um recorte extraído das informações oferecidas pelo Plano Individual de Atendimento (PIA), com o objetivo de analisar no material os indicativos de que esses jovens estão submetidos a um processo de acúmulo de desvantagens. Questiona-se, assim, a capacidade efetiva do sistema socioeducativo de reeducar esses jovens e modificar a suas trajetórias de vida.

PALAVRAS-CHAVE: Adolescência; Criminalidade; Sociologia; Psicologia; Trajetórias de vida.

RESUMEN: Este texto pretende pensar las articulaciones entre el curso de vida y, principalmente, la trayectoria infraccional de adolescentes que cumplen medida socioeducativa de Internación y Semilibertad por tráfico de drogas en una ciudad de Minas Gerais, Brasil. Orientado, en el ámbito de la Sociología, por la criminología de curso de vida y, en el ámbito de la Psicología, por la escucha de la singularidad de la vida adolescente, este trabajo presenta una perspectiva extraída de las informaciones del Plan Individual de Atendimiento (PIA) con el objetivo de analizar en el material los indicativos de que esos jóvenes están sometidos a un proceso de acúmulo de desventajas. Se cuestiona, así, la capacidad efectiva del llamado sistema socioeducativo de revertir su trajectoria de infracción.

PALABRAS-CLAVE: Adolescencia; Criminalidad; Sociología; Psicología; Trayectorias de vida.

ABSTRACT: This theoretical essay reflects on the articulations between life trajectories and, mainly, the infringement path amongst adolescents who are currently in deprivation or restriction of liberty for infringing Brazilian laws on drug dealing. Guided, in the field of Sociology, by life trajectory criminality, and, in the field of Psychology, by actively listening to the singularities of teenagers' lives, this text presents a selection of information provided by the Plano Individual de Atendimento (Individual Plan of Care - PIA) aiming to analyze in this material elements which can possibly indicate that these adolescents have been submitted to a process of accumulation of disadvantages. We question, thus, the effectiveness of Brazilian so-called socio-educational system in its purpose of reeducating these young people and changing their life trajectory.

KEYWORDS: Adolescence; Criminality; Sociology; Psychology; Life Course. 


\section{Curso de vida em perspectiva}

A mudança social causada pelo contexto de modernização no início do século XX chamou atenção da primeira geração de pesquisadores da Escola de Chicago. Eles perceberam que eventos estruturais como migração, guerras e crises econômicas influenciavam as coortes e alteravam o curso de vida dos indivíduos. Nesse contexto, resgatar a dimensão temporal na análise permitia situar os sujeitos historicamente e compreender o impacto comum de eventos e circunstâncias (Elder, 1985).

O uso da dimensão temporal como categoria analítica também se mostra interessante uma vez que o envelhecimento e o desenvolvimento são processos contínuos, isto é, o tempo existente entre nosso nascimento e morte é o período no qual nos desenvolvemos biológica, psicológica e socialmente. Cada cultura em cada época específica define expectativas e normas para cada faixa etária. As contemporâneas sociedades urbanas também estabelecem algumas normas e expectativas que marcam transições e dividem nossas vidas em diferentes trajetórias. Por exemplo, entrar na escola inaugura nossa trajetória escolar, a paternidade uma outra trajetória no curso de vida. Assim, as transições mais evidentes são aquelas marcadas por eventos que estão inseridos dentro das trajetórias no curso de vida de cada indivíduo. Os eventos, a depender de uma série de fatores como sua natureza, duração e os recursos, motivações, crenças e definições que o agente traz para a situação, podem mudar o curso de vida de um indivíduo. Dessa maneira, para Elder (1985) a dinâmica do curso de vida se dá através da relação de interdependência entre as trajetórias e as transições, sendo possível observar padrões, apesar das particularidades de cada história individual.

Para Benson (2012), a pesquisa e a teorização dentro dessa perspectiva, além da agência humana, devem levar em conta mais três princípios. O primeiro deles é o princípio da idade. As expectativas e normas para a performance individual, assim como o controle social e o peso que os eventos podem ter no curso de vida variam conforme a idade (Hogan, 1980). O tratamento dispensado a um jovem apreendido com drogas aos 11 anos, por exemplo, será diferente daquele recebido por um adulto de 35 anos na mesma situação. Para Benson (2012) isso se deve ao fato de que os mais velhos possivelmente possuem maior capital humano e um comportamento mais conformista, capacitando-os para se desvencilhar do rótulo de desviantes.

O segundo princípio é o das vidas ligadas. Os seres humanos estão conectados uns aos outros em teias de interdependência que dão origem a configurações variadas como a família, trabalho ou o próprio meio cultural. Dessa forma, as redes exercem influências variadas sobre nossas vidas, uma vez que incentivam ou restringem alguns atos e comportamentos (Granovetter, 1985). Além disso, eventos e mudanças na vida dessas pessoas também podem impactar nossa própria trajetória (Elias, 2008).

Por fim, está o lugar e tempo histórico. Situar os indivíduos num contexto histórico e geográfico específico permite uma compreensão sobre como estes delimitam a ação individual, permitindo também um entendimento mais apurado do impacto de determinados eventos e circunstâncias. 


\section{Compreendendo trajetórias infracionais através do curso de vida}

Autores como Sampson e Laub (1997), se apropriaram da perspectiva do curso de vida para compreender trajetórias infracionais. ${ }^{1}$ Essa apropriação tem como plano de fundo a seguinte questão: o comportamento antissocial na infância seria um preditor de comportamento antissocial na fase adulta?

Para certas correntes sociológicas da criminologia, nomeadamente a Teoria do Autocontrole de Gottfredson e Hirschi (1990), ao partir de concepções estáticas, consideram que o comportamento desviante é estável porque teria origem em traços latentes da personalidade formados durante a infância e que supostamente não variam ao longo do tempo. Por sua vez, Sampson e Laub (1997) chamam atenção, entretanto, para o papel dos turning points como eventos capazes de transformar a rede de relações e os papéis assumidos pelos indivíduos, produzindo assim mudanças individuais, em contraposição à ideia de estabilidade comportamental.

Dessa maneira, estes autores advogam a favor de uma perspectiva desenvolvimental, isto é, que busca ao mesmo tempo compreender a questão da mudança individual como algo organizado e sistematizado em torno de expectativas relacionadas ao processo de envelhecimento e como essas mudanças - especialmente relacionadas a comportamentos - põem em funcionamento processos dinâmicos que alteram resultados futuros no curso de vida dos indivíduos. Para tanto, revisitam a teoria dos rótulos, que, por conta da sua ênfase em processos ao longo do tempo, seria a única teoria verdadeiramente desenvolvimental dentro do campo da sociologia criminal.

Seguindo a formulação clássica de Becker (2008), o primeiro passo para o início de uma carreira desviante é o cometimento intencional de um ato desse tipo. Dessa forma, não basta o cometimento de um ato não intencional e nem mesmo eventual. Para além da intencionalidade, Becker enfatiza, o aprendizado de motivos e interesses através da interação com outros desviantes como um dos mecanismos que levam da experimentação casual a um padrão mais permanente de comportamento.

Finalmente, é preciso considerar os casos em que uma pessoa mantem oculto da sociedade seu comportamento desviante, sem que isso lhe gere maiores consequências. No entanto, uma vez descoberto, o desvio gera reações sociais, que podem excluir e estigmatizar o agente. Assim, um dos passos mais decisivos para a construção de um padrão de comportamento desviante é a experiência de ser acusado e rotulado publicamente. $\mathrm{O}$ rótulo de desviante - a depender dos recursos disponíveis ao indivíduo - adere ao agente definindo sua identidade pública, impedindo que participe de grupos mais convencionais. Isso acaba por impelir o estreitamento de laços com grupos desviantes e a realização de novos atos desviantes.

Na mesma linha, Sampson e Laub (1997) afirmam que os comportamentos desviantes são embasados em estilos de interação sustentados pela repetida reação dos outros durante as relações sociais recíprocas (continuidade interacional) e a progressiva acumulação das suas consequências (continuidade cumulativa). Esse processo leva ao que os autores chamam de "acúmulo de desvantagens", que tem como efeito o enfraquecimento dos laços que ligam os indivíduos a instituições convencionais como família, escola e mercado de trabalho. 
Assim sendo, eventos episódicos ou contínuos como a violência doméstica, o abandono escolar, o encarceramento e a mudança residencial, podem ser pontos de virada diretamente relacionados ao engajamento na trajetória criminal. Por outro lado, eventos como conseguir um emprego, servir ao exército ou casar-se podem ser enxergados como oportunidades de dar fim a essa trajetória. Assim, se o crime é mais provável quando os laços sociais estão fracos ou quebrados, eventos como estes reorganizam os laços interpessoais, explicando assim as mudanças relacionadas à trajetória infracional.

Portanto, a continuidade e a estabilidade do comportamento antissocial não estariam necessariamente ligadas a características imutáveis da personalidade individual, mas ao processo cumulativo de desvantagens, e aos laços estabelecidos em seu curso de vida, que levam o indivíduo a ser progressivamente excluído ou incluído das oportunidades convencionais.

\section{Tempo Histórico, Lugar e Motivações: Um panorama}

No contexto brasileiro, apesar das diferenças históricas, socioeconômicas, culturais e criminais, o comércio ilegal de drogas parece vinculado a áreas de alta concentração de desvantagens, com histórico de ocupação precária e desordenada, marcados por uma relação ambígua de abandono e resistência contra o poder público (Silva, 2014).

Nesse contexto a estruturação das atividades criminosas se daria seguindo um roteiro com três atos (Beato, \& Zilli, 2012). No primeiro ato, temos o crime desorganizado e o conflito entre gangues. Caracteriza-se por uma baixa complexidade das atividades ilícitas, pouca articulação entre agentes e grupos delinquentes e os primeiros germens de esquemas de corrupção e violência policial.

O segundo ato se caracterizaria pela competição e possível extinção de determinado grupo, na medida em que alguns grupos podem tentar se impor pela força sobre os outros, instaurando ciclos de enfrentamento marcados pela disputa violenta. Há também uma predominância cada vez maior de uma lógica econômica e aumento da complexidade na ação propiciado pela articulação entre as gangues que atuam nas favelas, os criminosos no sistema prisional e agentes estatais (Beato \& Zilli, 2012; Feltran, 2008).

No terceiro e último ato, há uma tentativa de minimizar conflitos entre grupos seja por formas radicais de controle do mercado, como a eliminação ou prisão de competidores, ou por táticas conciliatórias, como a instaurada pelo Primeiro Comando da Capital (PCC) em São Paulo. Nesse caso, a facção funciona como uma espécie de mediador de conflitos do mundo do crime. Segundo autores como Feltran (2008) e Malvasi (2012), essa ação parece ter pacificado o mercado, além de demonstrar uma maior institucionalização da lógica econômica.

Independentemente do ato encenado em cada situação, a presença das 'biqueiras'”, assim como de outras ilegalidades, parece ser encarada com certa naturalidade em algumas periferias urbanas brasileiras. Um exemplo dessa naturalização é a descrição feita pelo rapper MV Bill, que durante visita a uma comunidade para a gravação do documentário Falcão, Meninos do Tráfico, presenciou as crianças do lugar brincando de tráfico de drogas. É impressionante a descrição dos detalhes, em que as crianças reproduzem o ambiente que as rodeia: armas de fogo de brinquedo, 'endolas', pagamento de arrego, e o tratamento dispensado aos alcaguetes. (Bill \& Athayde, 2006) 
Assim, o envolvimento com a criminalidade pode ser fonte de status e prestígio social, uma vez que "o tráfico é uma atividade que compõe tendências atuais de consumo, estilo de vida e valores recorrentes entre jovens de todo o mundo" (Malvasi, 2012, p. 68). O envolvimento também pode representar uma resolução para a precariedade material em que muitos adolescentes se encontram. Assim, a inserção no mercado das drogas oferece não apenas uma fonte de renda, como também um plano de carreira para aqueles jovens que sentem a obrigação ou o anseio de se tornarem independentes ainda em tenra idade, representando uma forma de ascensão social mais palpável que a escolarização (Lyra, 2013).

De outro lado, a ausência de uma política sobre drogas realista que vislumbre, ao invés da proibição total, algum tipo de regulamentação, faz com que o mercado das drogas se torne uma máquina de produzir delinquência num contexto de exacerbada desigualdade social. Somente no ano de 2015, o tráfico representou o maior motivo de entrada de adolescentes no sistema de Justiça Juvenil em Belo Horizonte, sendo responsável por 25\% dos atos infracionais apurados, segundo dados do Centro Integrado de Atenção ao Adolescente Autor de Ato Infracional de Belo Horizonte/MG (CIA-BH, 2016).

\section{Metodologia}

A realização desse trabalho foi possibilitada por conta da pesquisa "A trajetória de vida de adolescentes e jovens envolvidos nos crimes de roubo e políticas de prevenção" A amostragem dessa pesquisa foi feita por conveniência e recolheu dados quantitativos e qualitativos de processos que transitaram em julgado na Vara da Infância e Juventude de Belo Horizonte através da técnica de análise de conteúdo documental. Foram recolhidas informações de 373 adolescentes, sendo $88,5 \%$ do sexo masculino e $80 \%$ classificados como pretos ou partos. Cerca de $52,5 \%$ dos jovens residia apenas com a mãe e $55,2 \%$ delas tinham escolaridade inferior a nove anos de estudo. Desse modo, grande parte das mães trabalhavam em ocupações de baixo status socioeconômico como domésticas, faxineiras ou auxiliares de serviços gerais. Não há informações sobre $71,6 \%$ dos pais, sendo que os poucos sobre os quais há dados estatísticos verifica-se mesma tendência que a observada entre as mães: baixa escolaridade e ocupações manuais precárias. O perfil da amostra indica um maior foco da justiça criminal nos delitos cometidos por adolescentes pobres. (Paula, 2014)

A partir do recorte proposto - adolescentes cumprindo medida socioeducativa em meio fechado por tráfico de drogas - Selecionamos o universo de 17 casos, no qual temos informações sobre 16 adolescentes do sexo masculino e uma adolescente do sexo feminino. Essas informações foram obtidas através dos relatórios elaborados pela equipe do Plano Individual de Atendimento (PIA), cedidos pelo Centro Integrado de Atendimento ao Adolescente Autor de Ato Infracional (CIA-BH), documento obrigatório instituído através da lei do SINASE ${ }^{5}$ e elaborado sob a responsabilidade da equipe técnica da unidade de atendimento. Segundo esta lei, o objetivo do PIA é orientar a realização de um diagnóstico interdisciplinar e multidimensional a partir da trajetória infracional, familiar, escolar, laboral e médica dos adolescentes, servindo como guia para a execução das medidas socioeducativas. 
No PIA, o sujeito transformado em caso, torna-se um objeto passível de ser individualizado, medido, categorizado, comparado e agrupado segundo suas qualidades, competências e aptidões, demonstrando concretamente a incorporação de conhecimentos médicos, pedagógicos, psicológicos, e outros, aos saberes jurídicos. Portanto, podemos dizer que se trata de um exame tal qual descrito por Foucault (1996), em que a superposição das relações de saber e de poder assume todo o seu brilho visível.

Dessa maneira, embora estejamos interessados nas informações relativas aos adolescentes, o PIA deve ser interpretado dentro do seu lugar de fala, ou seja, como a voz dos saberes incorporados pelo sistema judicial. Essa voz, como veremos, por vezes emerge da simples descrição das trajetórias para tecer comentários, avaliações e até mesmo formular diagnósticos sobre os jovens analisados, apresentando, assim, um forte conteúdo normativo. Desse modo, os procedimentos e técnicas socioeducativas revelam uma racionalidade governamental capaz de capilarizar suas formas de poder até a moradia e o núcleo familiar dos adolescentes (Malvasi, 2012).

A vertente da lógica normativa pode ser localizada na proposição deste instrumento no que tange à construção de um projeto de vida com base no sistema de garantia de direitos, que, segundo Moreira et al. (2015b), nos leva a compreender este instrumento "como produtos de uma racionalidade técnica-instrumental, sendo que a razão instrumental opera com eficiência, mas não deixa espaço para as manifestações da subjetividade” (p. 348).

Moreira et al. (2015b) nos lembram, portanto, que, quando a escuta é também um dispositivo que orienta o trabalho com esses adolescentes, o PIA deve dar "voz" ao adolescente, criando possibilidades de compreender sua trajetória de vida e, a partir dela, propor a construção de novos objetivos e laços frente à medida socioeducativa.

Castro e Guareschi (2008), também afirmam a importância do lugar da escuta ao entenderem a maneira como os adolescentes dão significado a suas práticas de vida e se subjetivam no cumprimento da medida socioeducativa. Para os referidos autores, "a trajetória de vida dos adolescentes considerados autores de atos infracionais é geralmente caracterizada por sucessivas situações reais e subjetivas de exclusão” (p. 204), e, dessa forma, "não há indícios de que trajetórias de vida tão difíceis e repletas de perdas, faltas e privações possam sofrer qualquer forma de mudança sem o respeito à singularidade” (Castro \& Guareschi, 2008, p. 206).

A narrativa apresentada a seguir tenta capturar as semelhanças entre os casos analisados. Também procuramos - na medida do possível - capturar algumas peculiaridades, sendo uma das ações nesse sentido a identificação dos sujeitos de pesquisa conforme sua idade, cor/raça, situação de residência e escolaridade. Por fim, no intuito de preservar a identidade dos adolescentes, trocamos os nomes dos jovens, de seus parentes, dos bairros e das escolas de todos os excertos, por iniciais aleatórias.

Parece-nos importante ressaltar que não desconsideramos os atravessamentos sociais, políticos, econômicos e culturais que compõe a vida destes jovens e suas trajetórias infracionais. Mas, por vezes, estes elementos não são contemplados pela equipe técnica responsável pela construção do PIA, produzindo um efeito problemático de desconsiderar a trama social tecida na construção do ato infracional. 


\title{
Apresentação e discussão dos resultados
}

Nossas trajetórias de vida são influenciadas pelas pessoas que estão ligadas a nós, seja por laços de parentesco ou afeição. Assim, os eventos e mudanças na vida de pessoas a quem estamos relacionados têm impacto sobre nossa própria trajetória. A partir dessa ideia e considerando o que Castro e Guareschi (2008) nos lembram sobre os modos como os adolescentes significam suas práticas de vida e se subjetivam a partir dos contextos da família, da justiça e da medida socioeducativa após o cometimento da infração e no cumprimento da medida, buscou-se entender como a equipe técnica responsável pela feitura do PIA avalia as relações entre esses adolescentes e seus familiares:

\begin{abstract}
A família do adolescente tem acompanhado de forma mais próxima o cumprimento dessa medida. Estão realizando frequentemente as visitas semanais ao adolescente, e ele utiliza também da ligação semanal para continuar o vínculo. Suas referências familiares também são duas tias maternas, as quais o adolescente cita nos atendimentos. A tia $\mathrm{C}$, para o adolescente, é uma figura que já o acompanhou em outras medidas já aplicadas a ele. Esta pessoa é presente no discurso do adolescente quando o mesmo constrói perspectivas fora da criminalidade. ( $\mathrm{P} 4^{6}$, 17 anos, pardo, reside com a mãe, 7 E. $\mathrm{F}^{7}$ )
\end{abstract}

Neste caso, embora a família se mostre comprometida com visitas e ligações, as tias, e não os genitores são as referências que ajudam o adolescente a projetar uma outra vida. Dentro do universo analisado são comuns relatos de 'famílias quebradas' por conta de eventos como a morte ou abandono efetivo/afetivo por parte de um dos genitores, geralmente os pais. Assim, as presenças ou ausências da família durante o cumprimento da medida socioeducativa servem como base para a avaliação dos vínculos afetivos:

A família apresenta laços afetivos frouxos; os pais não trazem os irmãos para visita. $\mathrm{R}[\mathrm{P} 7]$ não sabe as idades dos irmãos, tampouco outras informações, por exemplo, se eles estudam, participam de algum projeto social, enfim, para $\mathrm{R}$ é como se a família estivesse aguardando para quando ele precisar, não há reciprocidade. Sendo assim, a equipe avalia a importância da manutenção de atendimento familiar e possibilidade de visita técnica. (P7, 17 anos, preto, reside com a mãe e o padrasto, 4 E. F.)

A fragilidade dos laços familiares é tema central em todos os casos analisados. No trecho anterior, embora os técnicos apontem os fatos da ausência dos irmãos e do desconhecimento por parte do adolescente de informações básicas sobre eles como indício dessa fragilidade, é importante perguntar em que medida a própria institucionalização pode promover o afrouxamento dos laços familiares. Para a equipe técnica, a falta de coesão familiar demandaria uma intervenção continuada.

Segundo Souza e Costa, em pesquisa acerca do tema da família de jovens envolvidos com a criminalidade, "as famílias estão abrindo mão da socialização das crianças cada vez mais cedo, não tendo a sociedade ainda desenvolvido fontes extrafamiliares adequadas de socialização e apoio" (Souza \& Costa, 2013, p. 281). As autoras trazem ainda o conceito de "filho parental" para pensar o lugar que alguns desses adolescentes ocupam na estrutura familiar, sendo convocados a assumir precocemente funções que deveriam ser da alçada dos adultos e desempenhar diferentes papéis ao lado da mãe, como provedores e 
protetores, exatamente por causa do abandono paterno. Acrescenta-se a esse cenário o problema da "pobreza política" - termo usado por Pedro Demo (2006) -, que evidencia as dificuldades dessas famílias de romperem com o círculo da vulnerabilidade, pobreza, violência e criminalidade, na medida em que a sociedade e o Estado não constroem alternativas para minimização e superação das desigualdades sociais. Segundo Souza e Costa:

A noção de pobreza política sugere que a carência de cidadania possivelmente seja a dimensão mais grave nos pobres, porque essa carência impede que se tornem protagonistas de sua própria emancipação. Ou seja, ser pobre politicamente significa não se reconhecer enquanto sujeito de direito. (Souza \& Costa, 2013, p. 285)

A análise destes PIAs nos faz entender que as intervenções da equipe que acompanha os adolescentes representam um esforço de reaproximação dos mesmos e seus familiares, sendo este trabalho o eixo orientador da atuação do PIA.

Dessa maneira, além de avaliar os laços familiares, a equipe técnica busca desvios e atravessamentos nas trajetórias das pessoas relacionadas aos adolescentes que possam explicar o envolvimento desses jovens com a criminalidade:

O adolescente conta ainda que outros parentes são envolvidos com o tráfico, sendo que traficava para um primo, que atualmente encontra-se preso. Relata que dois irmãos mais velhos foram mortos pelo tráfico da região: $\mathrm{J}(16$ anos) e V (23 anos). $\mathrm{O}$ primeiro teria sido morto por comparsas e a segunda por delatar um traficante. (P5, 15 anos, pardo, reside com a mãe, 6 E. F.)

Além do envolvimento com o crime, o serviço técnico também se interessa por descobrir detalhes sobre saúde mental e uso de drogas pelos familiares dos adolescentes, sendo comuns nessa seleção relatos de genitores alcoólatras. O caráter normativo do diagnóstico dos técnicos do Sistema Socioeducativo a respeito da família mostra ao mesmo tempo quais são os papéis que uma família deve corresponder, e que, muitas vezes, esses papéis não são desempenhados pelas famílias desses jovens.

A relação com a escola também é dissecada sob o olhar clínico dos técnicos da Justiça Juvenil:

de acordo com relatos do adolescente, quando criança o socioeducando passou por uma creche, no bairro P, ficando por lá parte do dia e outra parte com a avó, pois sua genitora, a Sra. C, trabalhava fora. Aos 8 (oito) anos, deu início ao ensino fundamental na Escola Municipal L, localizada no bairro P. O adolescente fala com alegria ao lembrar-se da escola, das professoras, das excursões, e diz: "Era uma escola grandona! Tinha muita gente lá, eu gostava muito das professoras A $e$ B. A cantina era grande, tinha muita coisa boa, e até saíamos para passear". $\mathrm{O}$ adolescente ressalta que sempre gostava de estudar, que sempre foi um bom aluno e que não repetiu nenhum ano. Contudo, a Sra. C, em atendimento familiar, nos relata que o adolescente sofria de depressão e fazia uso de medicamentos controlados e ainda era vítima de bullying entre os colegas da escola. Diante das constantes violações de respeito sofridas, K agrediu um dos alunos da escola em que estudava sendo encaminhado para o Conselho Tutelar do bairro Horto. Após o episódio foi desligado da escola. (P6, idade e etnia não explicitadas, reside com a mãe e o padrasto, 8 E. F.) 
O tempo da infância na escola, normalmente idealizado como momento de pureza e inocência, se faz presente na fala infantilizada que traz a recordação afetiva acerca do espaço escolar. $\mathrm{O}$ adolescente que iniciou sua formação escolar tardiamente devido ao seu quadro de sofrimento mental, diante da omissão da escola quanto a prática do bullying, foi expulso da instituição após enfrentar aqueles que praticavam este ato contra ele.

Outro ponto frequente são os relatos de dificuldade de aprendizagem e indisciplina. Esses jovens, normalmente provenientes de famílias com baixa escolaridade, não representam a clientela considerada ideal da escola, visto que não conseguem atender à exigência de adaptação à instituição e adotar comportamentos tidos como adequados. Observa-se, ainda, contribuindo para esse quadro, uma ausência de tentativas partidas da instituição escolar no sentido de auxiliar os jovens que relataram dificuldades de aprendizagem.

Segundo Moreira et al. (2015a) um dos maiores desafios postos ao espaço escolar seria a proposição do reconhecimento humano, ou seja, uma atitude de não julgamento e indiferença das trajetórias de vida desses adolescentes que implique em acolher suas questões e "apostar em seu potencial e na possibilidade de fazerem novas escolhas que não envolvam a prática de atos infracionais” (p. 61). Assim, criando a possiblidade de incorporar a diferença como plataforma de ação educativa.

Podemos afirmar que o abandono e a exclusão escolar, diante da incapacidade das instituições educativas de lidar com a diferença, em idade precoce limita o acesso a oportunidades de emprego e profissionalização, representando assim mais uma desvantagem carregada por esses adolescentes na busca por inserção social. Além disso, a evasão escolar configura-se como um importante turning point na vida desses jovens, sendo fator comum a 16 dos 17 casos analisados. A evasão parece ainda coincidir com o início do uso de drogas por parte desses sujeitos e com o começo de sua trajetória infracional.

Silva e Bazon (2014) realizam um importante trabalho de revisão integrativa de literatura sobre as relações existentes entre a educação escolar e a conduta infracional em adolescentes, oferecendo as seguintes conclusões: (a) a associação entre a qualidade das experiências familiares, a adaptação escolar e a conduta na adolescência; (b) o relacionamento com professores e colegas como variável de base à vinculação escolar e protetiva ao envolvimento com a prática de delitos; (c) as sanções escolares como variável de base à desvinculação escolar e risco ao envolvimento com a prática infracional; (d) a associação entre bullying, problemas escolares e comportamento infracional na adolescência; (e) a evasão escolar e a conduta infracional (Silva \& Bazon, 2015, p. 279). Podemos acrescentar, ainda, a precariedade do sistema educativo, o descaso com o magistério, dentre outros elementos sociais importantes.

Diante do exposto e considerando que o insucesso escolar aliado ao envolvimento com as drogas e o tráfico são fatores que justificam a evasão escolar, tomaremos o caso a seguir como exemplo que contribui para a compreensão dos motivos que levam os jovens a abandonarem os estudos:

Em relação a trajetória escolar pregressa do adolescente, relata que está afastado da escola há aproximadamente três anos, e a última escola que frequentou foi a Escola Estadual J. S. L., à qual pontua que era assíduo. Apresentava um comportamento adequado para o ambiente escolar e respeitava alunos e professores. Quando questionado sobre a interrupção nos estudos, informa que repetiu o $6^{\circ}$ ano, começou a se envolver com atos ilícitos (drogas) e consequentemente abandonou os estudos. (P2, 16 anos, pardo, reside com o pai, 9 E. F.) 
A atratividade do tráfico de drogas aparece no discurso dos adolescentes traduzida em duas dimensões. A primeira delas é a dimensão financeira. Sem o apoio familiar e com baixa escolaridade, o tráfico de drogas aparece como uma fonte de renda que propicia a independência financeira desses jovens:

o adolescente não relata com detalhes seu envolvimento com a criminalidade, apenas declara ter sido pego no tráfico. $\mathrm{O}$ adolescente reconhece o quanto é difícil para ele sair do tráfico, porque fica "parasitando, sem trabalho e sem dinheiro; não quero ficar pedindo dinheiro minha mãe". (P11, 15 anos, preto, reside com a mãe, EJA)

A segunda dimensão refere-se ao status:

dentre as razões que o motivaram a iniciar na vida infracional ele aponta a necessidade de obter respeito, de ser alguém. $\mathrm{P}$ disse que assumiu postos altos na hierarquia do tráfico e que queria ser o melhor e o maior traficante da região. (P10, 16 anos, branco, reside com o pai, 9 E. F.)

É interessante notar que, para este adolescente, a carreira no tráfico de drogas aparece como um meio de alcançar reconhecimento e ascensão social, ocupando também o lugar de ambição profissional do adolescente. Nessa fala, também podemos perceber a organização do tráfico como análoga à de uma empresa, em que os postos estão distribuídos em uma hierarquia.

A Figura 1 nos permite visualizar a trajetória infracional e eventos relacionados as demais trajetórias em uma linha do tempo. Essa linha do tempo foi construída a partir dos eventos citados no PIA acompanhados por algum indicativo temporal. Através dela podemos especular sobre as relações entre eventos como o início do uso de drogas, a evasão escolar ou a morte de um familiar e o início do envolvimento infracional.

\section{Figura 1: Linha do tempo e trajetória infracional}

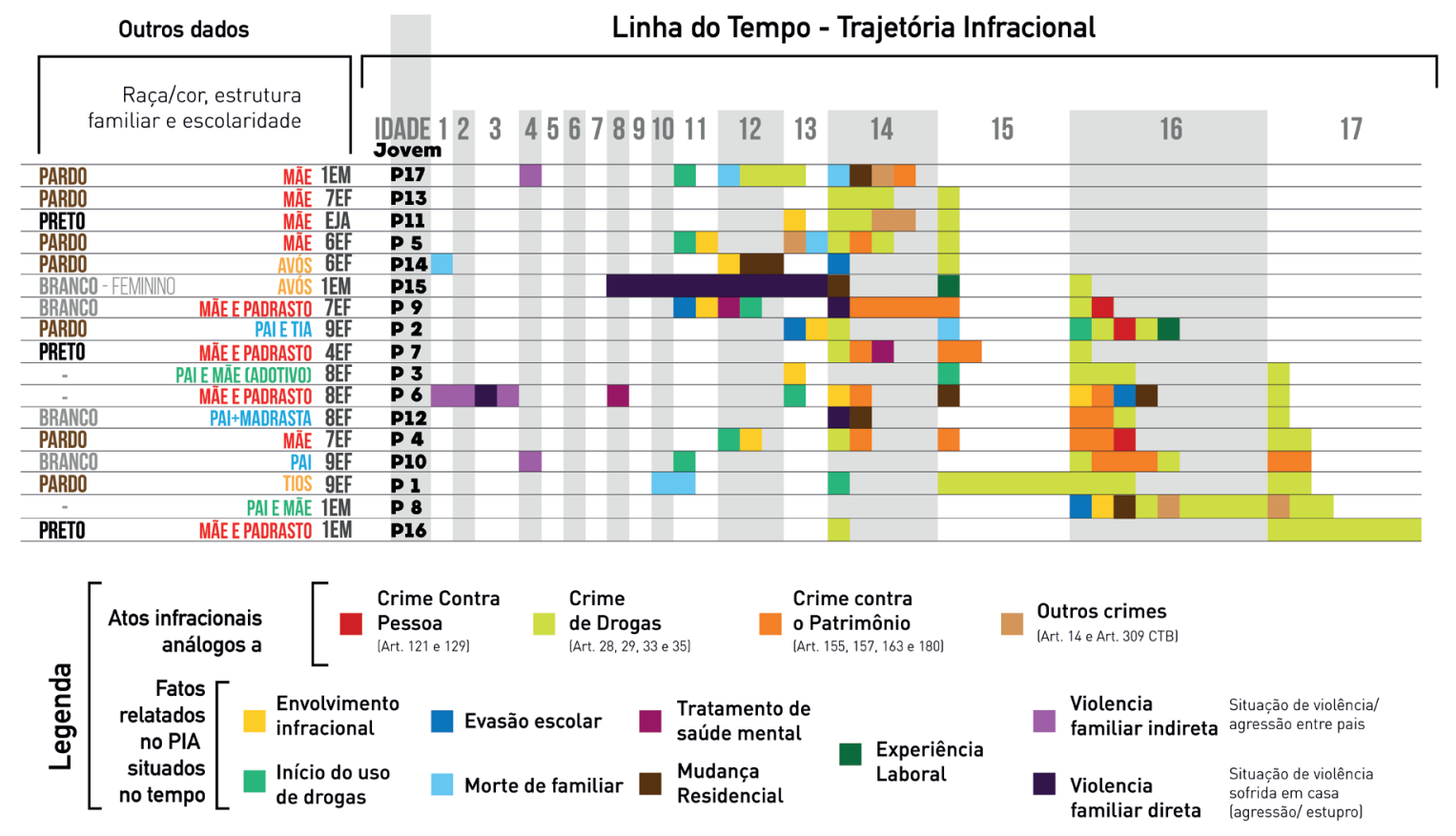


Para melhor compreender a trajetória infracional desses jovens, buscamos encará-la como uma sequência longitudinal de atos infracionais cometidos por um indivíduo, que pode ser descrita com base em quatro pontos: participação, frequência, seriedade e duração (Benson, 2012). A participação descreve a parcela da população que se engaja em atos infracionais, enquanto as outras três dimensões descrevem como se dá essa participação. Apesar de estarmos aqui considerando apenas participantes, temos necessariamente de levar em conta que a amostra da pesquisa em que este trabalho é baseado, é influenciada pelos vieses da Justiça Juvenil, que parece perseguir alguns tipos de delitos de certo estrato da população.

A frequência é uma variável-chave, uma vez que varia de acordo com a idade e o tipo de crime, sendo também um bom indicador sobre o grau de especialização em determinada atividade ilícita. A Figura 1 traz a distribuição percentual de apreensões por ato infracional para cada adolescente divididas pela idade em que o ato foi cometido ${ }^{8}$. Os adolescentes P14 e P15, apresentavam somente uma passagem, mas que culminou na medida de meio fechado. No entanto, P 14 relata trajetória infracional desde os 12 anos de idade, enquanto P15 não relata trajetória pregressa. Percebe-se também, que apenas P9 foi apreendido aos 12 anos e que quase $90 \%$ das passagens de P16 se deram aos 17 anos. O resultado agregado, isto é, o resultado do somatório de todos os indivíduos, indica que $73,7 \%$ das passagens dos adolescentes se deram entre os 14 e os 16 anos.

Ainda levando em conta a frequência, ao observar a Figura 1, podemos notar que seis indivíduos têm todas as suas passagens relacionadas aos atos infracionais análogos aos crimes de drogas (Art. 28, 29, 33, 35), o que indica alto grau de especialização nessa atividade. Além disso, o total agregado indica que o tráfico de drogas exerce grande atratividade sobre estes jovens.

A Figura 1 também permite observar a dimensão da seriedade, parâmetro que serve para compreender o potencial ofensivo dos indivíduos. Dessa maneira, nota-se que apenas três indivíduos têm passagens por atos infracionais análogos aos crimes contra a pessoa (Art. 121 e 129), sendo que este tipo de crime corresponde somente a $3 \%$ do volume agregado.

Por fim, a duração permite conhecer o nível de envolvimento dos sujeitos com a vida infracional. Embora a Figura 1 ofereça elementos para refletirmos sobre essa dimensão, somente uma pesquisa longitudinal prospectiva poderá revelar a extensão da trajetória infracional dos adolescentes aqui considerados.

Podemos dizer que é sobre este último eixo que a ação socioeducativa idealmente atua, através da tentativa de conduzir os socioeducandos a uma reflexão interna visando aquilo que o serviço técnico nomeia de responsabilização:

Durante este tempo de internação, o jovem verbaliza o desejo de se desvincular da dinâmica infracional, salientando que não aguenta mais ficar "preso", conforme expressa. Nesse contexto, reconhece que tem uma trajetória de constantes apreensões e descumprimento das medidas socioeducativas aplicadas. Todavia, ele não se responsabiliza pelos atos infracionais e logo não se implica no cumprimento da medida. ( $\mathrm{P} 8,17$ anos, etnia não explicitada, reside com pai e mãe, 1 E. M.) 
Apesar da reflexão sobre a trajetória infracional, o adolescente - segundo o serviço técnico - não reflete sobre si como produtor de suas ações, o que o levaria ao desengajamento da medida, bem como a uma visão apenas punitivista sobre esta. Isto é demonstrado em sua fala que ignora a linguagem eufemística do sistema socioeducativo. No entanto, outros adolescentes parecem efetivamente encarar o processo socioeducativo como uma chance de reinserção social:

o adolescente enxerga a MSE [Medida Socioeducativa] como um momento de reflexão e oferta de oportunidades. Desse modo, para L efetivamente se responsabilizar, ele precisa de orientações sobre encaminhamentos que demonstrem novas oportunidades de vida. (P14, 15 anos, pardo, reside com a avó, 6 E. F.)

Segundo Souza (2015), de maneira geral, ao retratarem no PIA a vertente da responsabilização, as equipes trabalham com o objetivo de possibilitar ao adolescente uma conscientização sobre sua responsabilidade enquanto comprometimento com a medida. Esse comprometimento possibilitaria as condições para a não reincidência na prática infracional. Contudo, faz-se necessário ir além da compreensão da responsabilização. É preciso considerar a singularidade convocando o adolescente a falar e construir um saber sobre suas trajetórias de vida marcadas pelo mal-estar que o afeta e ao qual responde via ato infracional.

Assim, o conteúdo expresso nessa fala indica que para a responsabilização ser concluída, além de reflexão, é preciso que os adolescentes e o Estado, via sistema socioeducativo e suas articulações institucionais, se dediquem a buscar outros caminhos. Nesse contexto, a intervenção do serviço técnico se dá no sentido de explorar fatos acerca da trajetória laboral dos adolescentes:

Em relação às experiências laborais, $K$ informa ter realizado um trabalho informal juntamente com o seu genitor, como ajudante de pedreiro no ano de 2012 (não lembra o período), em que recebia a quantia de $\mathrm{R} \$ 50,00$, e pontua que utilizava o dinheiro para comprar chinelo e roupas. ( $\mathrm{P} 2,16$ anos, pardo, reside com o pai, 9 E. F.)

A realização de trabalhos informais, normalmente ligados à área da construção civil, é ponto comum entre muitos adolescentes da seleção feita para este trabalho, sendo também um indicativo da classe social de que eles provêm e das dificuldades enfrentadas para o acesso ao mercado de trabalho. Diante da pouca qualificação profissional desses jovens, a intervenção socioeducativa procura estimulá-los e encaminhá-los para cursos e oficinas:

$\mathrm{O}$ adolescente tem desejo de fazer cursos de mecânica, lanternagem, pintura de parede e de carro. Disse que gostaria de ter oportunidade de conseguir bons empregos. A equipe de referência irá investir neste aspecto da medida de B. O próprio adolescente afirma que uma das causas de sua entrada no tráfico de drogas foi a condição financeira difícil da família. E desde o início do cumprimento de sua medida demonstra o desejo de realizar cursos profissionalizantes como uma forma concreta de sair da vida infracional. (P1, 17 anos, pardo, reside com a avó, 9 E. F.) 
Assim, a formação profissional surge como uma oportunidade de alterar o curso de vida dos adolescentes, pois o discurso da profissionalização nos remete à ideia de recuperação pelo labor, que promove a inclusão possibilitando a ruptura com a prática infracional. No entanto, embora existam ofertas de cursos profissionalizantes dentro do sistema socioeducativo, constatamos que essas ofertas se restringem a cursos básicos de informática, cabeleireiro, padeiro ou garçom. Estão, portanto, muito aquém das expectativas dos jovens e explicitam o papel do Sistema Socioeducativo na reprodução do sistema de classes.

Por fim, a última esfera da vida discutida pela equipe técnica da Justiça Juvenil é a da saúde:

$\mathrm{O}$ adolescente chega na unidade em boas condições de higiene, verbalizando orientado em tempo e espaço. Não apresenta demandas afeitas à saúde. Relata uso de aparelho odontológico retirado em outra unidade. Quanto ao uso de drogas o mesmo relata uso de maconha desde os 11 anos, não apresentando interesse em tratamento. Desconhece alergias medicamentosas. Será encaminhado ao Centro de Saúde para realizar triagem odontológica e acompanhamento pela equipe de saúde bucal. Também será encaminhado para realizar consulta médica com vistas à promoção e prevenção da saúde do adolescente. (P 17, 17 anos, pardo, reside com a mãe, 1 E. M.)

Os adolescentes são avaliados literalmente da cabeça aos pés e questionados sobre vida sexual e consumo de drogas. O caso de P17 ilustra dois pontos comuns entre muitos dos casos analisados: a demanda por tratamento odontológico e a recusa à oferta de inserção em tratamentos toxicológicos.

Outro tópico interessante presente nesse eixo avaliativo são as considerações a respeito da saúde mental de alguns adolescentes:

Quanto ao aspecto cognitivo e mental, observa-se funcionamento precário. Neste sentido será encaminhado ao Centro de Atenção Psicossocial - CAPSi, neste município. Sobre histórico pregresso de saúde, em março de 2013 foi avaliado e consta relatório no seu prontuário socioeducativo com os seguintes dados: apresenta déficit de adaptação na escola, comportamento agressivo e distúrbio comportamental sem quadro psiquiátrico evidente. Usuário de drogas. O padrasto afirmou que $\mathrm{R}$ foi diagnosticado com Déficit de Atenção e Hiperatividade - TDAH. Constam encaminhamentos tanto para inserção em acompanhado em oficinas terapêuticas com profissional da equipe de saúde mental do PSF próximo onde mora, e encaminhamento ao CAPUT em Belo Horizonte, porém sem efetivação para os tratamentos. Foi realizado contato telefônico no CAPUT e apurou-se que o adolescente não foi inserido porque não compareceu na acolhida. (P7, 17 anos, preto, reside com a mãe e o padrasto, 4 E. F.)

A equipe técnica demonstra sua visão normativa acerca do que deve ser um funcionamento mental adequado, além de sugerir que o quadro de sofrimento mental do adolescente é a causa de seu comportamento de inadequação às normas sociais. Além disso, percebe-se mais um caso de omissão da família, que mesmo após diagnósticos e encaminhamentos, não se mobilizou para inseri-lo nos tratamentos oferecidos pela rede socioassistencial. 


\section{Considerações finais}

A apresentação das trajetórias de vida de adolescentes em cumprimento de medida socioeducativa permitiu elaborar uma narrativa transversal a todos os casos. Essa narrativa demonstra que a história de vida desses adolescentes, de modo geral e por motivos diversos, é marcada pela fragilidade dos vínculos com os familiares, principalmente os pais, gerando situações de apatia e negligência. Também mostra que a forma como a escola lida com problemas como o bullying, a indisciplina, a dificuldade de aprendizagem e outras questões típicas da juventude, acaba muitas vezes culminando na exclusão desses adolescentes do espaço escolar. Dessa maneira, a evasão escolar aparece como um turning point associado ao início precoce do uso de drogas e da trajetória infracional desses jovens.

Nessa perspectiva, diante dos fracos vínculos com a família e a escola que geram e reforçam um processo de acúmulo de desvantagens, e na ausência de uma política sobre drogas realista - que busque regulamentar ao invés de proibir -, o mercado das drogas se apresenta aos adolescentes como fonte de dinheiro e status, fornecendo bases para sua independência, inserção no consumo e formação da identidade. Nesse contexto, o Sistema Socioeducativo, talvez por conta do histórico de insucesso escolar de sua clientela ou por falta de investimentos, parece oferecer opções limitadas - principalmente no tocante à profissionalização - diante daquilo que o tráfico é capaz de prometer a esses adolescentes.

Por fim, é importante dizer que, embora estivéssemos desde o início interessados nas trajetórias de vida dos jovens, por conta da natureza dos documentos que serviram de base para este trabalho, foi impossível ignorar as opiniões, avaliações e o conteúdo normativo presente no discurso da equipe técnica. Assim, podemos afirmar que a avaliação crítica por parte dos técnicos das medidas socioeducativas se apresenta como um elemento na trajetória de vida, mas não necessariamente um ponto de virada e de escolha para um novo direcionamento, porque, por vezes, os relatórios simplesmente relatam e observam situações, tendo baixo potencial de intervenção. 


\section{Notas}

1 Entendemos trajetória infracional como uma sequência longitudinal de atos infracionais cometidos por um indivíduo. Para Benson (2012), esta trajetória é caracterizada por quatro dimensões: participação, frequência, seriedade e duração.

2 Consiste no local onde se vende droga, também conhecido como "boca de fumo".

3 Fracionamento de drogas em porções menores destinadas à venda

4. FAPEMIG - EDITAL 01/2014 - DEMANDA UNIVERSAL” PROCESSO N. : CSA - APQ-00175-14

Lei n. 12.594/ 2012.

6 Para preservar sua identidade, optamos por utilizar a letra $\mathrm{P}+$ numeral para designar cada um dos adolescentes. Nos relatórios do PIA, estes adolescentes são designados por letras, como se pode notar pelos trechos reproduzidos neste artigo.

7 Em todas as menções aos adolescentes, utilizar-se-ão, ao final, um numeral e uma sigla que identificarão a etapa escolar em que se encontram. E. F.: Ensino Fundamental; E. M.: Ensino Médio; EJA: Educação de Jovens e Adultos.

\section{Referências}

Beato, C. \& Zillii, L. F. (2012). A estruturação de atividades criminosas: um estudo de caso. Revista Brasileira de Ciências Sociais, 27(80), 71-88.

Becker, H. S. (2008). Outsiders: estudos de sociologia do desvio. Rio de Janeiro: Jorge Zahar. Benson, M. L. (2012). Crime and live course: an introduction (2nd ed.). New York: Routlegde. Bill, M. V. \& Athayde, C. (2006). Falcão: meninos do tráfico. Rio de Janeiro: Objetiva. Castro, A. L. S. \& Guareschi, P. (2008). Da privação da dignidade social à privação da liberdade individual. Psicologia \& Sociedade, 20(2), 200-207.

CIA-BH. (2016). Relatório Estatístico 2016. Belo Horizonte: Tribunal de Justiça do Estado. Recuperado em http://www.tjmg.jus.br/lumis/portal/file/fileDownload.jsp?fileId=8A80E40B6 B1E2170016B238067937AE9

Elder, G. H. (1985). Perspectives on life course. Ithaca, NY. Cornell University Press.

Elias, N. (2008). Introdução à Sociologia. Lisboa: Edições 70.

Demo, P. (2006). Pobreza política: a pobreza mais intensa da pobreza brasileira. Campinas, SP: Autores Associados. 
Feltran, G. S. (2008). O legítimo em disputa: As fronteiras do "mundo do crime" nas periferias de São Paulo. Dilemas - Revista de Estudos de Conflito e Controle Social, 1(1) 93-126.

Foucault, M. (1996). Vigiar e Punir. Petrópolis, RJ: Vozes.

Granovetter, M. (1985). Economic Action and Social Structure: the problem of embeddedness. American Journal of Sociology, 91(3), 481-510.

Gottfredson, M. \& Hirschi, T. (1990). A general theory of crime. Stanford: Stanford University Press.

Hogan, D. P. (1980). The transition to adulthood as a career contingency. American Sociological Review. 45(2), 261-276.

Lyra, D. (2013). A República dos meninos: juventude, tráfico e virtude. Rio de Janeiro: Mauad; FAPERJ.

Malvasi, P. A. (2012). Interfaces da vida loka: um estudo sobre jovens, tráfico de drogas e violência em São Paulo. Tese de Doutorado, Programa de Pós-graduação em Saúde Pública, Universidade de São Paulo, São Paulo.

Moreira, J. O., Albuquerque, B. S., Rocha, B. F., Rocha, P. M., \& Rocha, A. C. F. R. (2015a). A escola e a semiliberdade: a importância do diálogo. Psicologia em Revista, 21(1), 50-65.

Moreira, J. O., Albuquerque, B. S., Rocha, B. F., Rocha, P. M., \& Vasconcelos, M. A. M. (2015b). Plano Individual de Atendimento (PIA) na perspectiva dos técnicos da semiliberdade. Serviço Social \& Sociedade, 122, 341-356.

Paula, L. (2014). Justiça Juvenil. In R. S. Lima, J. L. Ratton, \& R. G. Azevedo (Org.), Crime, Polícia e Justiça no Brasil (pp. 450-461). São Paulo: Contexto.

Sampson, R. J. \& Laub, J. H. (1997). A Life Course Theory of Cumulative Disadvantage and Stability of Delinquency. In T. Thounberry (Ed.), Developmental Theories of Crime and Delinquency (pp. 1-29). New Brunswick: Transaction.

Silva, B. F. A. (2014) Social Disorganization and Crime: Searching for the Determinants of Crime at Community Level. Latin American Research Review, 49(3), 218-230.

Souza, J. M. P. (2015). Responsabilização do adolescente no cumprimento da medida socioeducativa: enlaces da Psicanálise com o Direito. Tese de Doutorado, Programa de Pós-graduação em Psicologia, Pontifícia Universidade Católica de Minas Gerais, Belo Horizonte.

Souza, L. A. \& Costa, L. F. (2013). A significação das medidas socioeducativas para as famílias de adolescentes privados de liberdade. Psico-USF, 18(2), 277-287. Recuperado de http:// www.scielo.br/pdf/pusf/v18n2/v18n2a11.pdf

\section{LUCAS CAETANO PEREIRA OLIVEIRA}

https://orcid.org/OOOO-0001-6587-0937

Mestre em Sociologia pela Universidade Federal de Minas Gerais (UFMG) e graduado em Ciências Sociais pela mesma instituição. Atualmente é pesquisador do Centro de Estudos de Criminalidade e Segurança Pública (CRISP). Possui experiência com o emprego de métodos quantitativos e qualitativos e tem interesse pelos seguintes temas: criminalidade, violência, conflito, desvio social, juventude, democracia e cidadania.

E-mail: kaetanolucas@gmail.com 


\section{JACQUELINE DE OLIVEIRA MOREIRA}

https://orcid.org/0000-0003-0901-4217

Possui graduação em Psicologia pela Universidade Federal de Minas Gerais (1992), mestrado em Filosofia pela Universidade Federal de Minas Gerais (1996) e doutorado em Psicologia Clínica pela Pontifícia Universidade Católica de São Paulo (2002), Pós-doutoramento em Teologia da Faculdade Jesuítas de Filosofia e Teologia. Atualmente é professora Adjunto da Faculdade de Psicologia da PUC Minas Gerais, professora do Programa de Pós-Graduação em Psicologia da PUC Minas. Atua principalmente nos seguintes temas: teoria psicanalítica, criminalidade juvenil, o tema da alteridade, sofrimento psíquico e pós-modernidade. Bolsista de Produtividade $\mathrm{CNPq}$ (categoria 2).

E-mail: jackdrawin@yahoo.com.br

\section{BRÁULIO FIGUEIREDO ALVES DA SILVA}

https://orcid.org/0000-0003-1791-9075

Possui graduação em Ciências Sociais pela Universidade Federal de Minas Gerais (2000), aperfeiçoamento em Análise Quantitativa pela Universidade do Texas em Austin (2003), mestrado em Sociologia pela Universidade Federal de Minas Gerais (2004) e doutorado em Sociologia pela Universidade Federal de Minas Gerais (2012). Atualmente é professor Adjunto do departamento de Sociologia da UFMG, pesquisador do Centro de Estudos de Criminalidade e Segurança Pública e do Centro de Pesquisas Quantitativas em Ciências Sociais da UFMG. Membro pesquisador do INCT Espaço Urbano e Gestão da Segurança Pública. Atua principalmente nos seguintes temas: gestão urbana, segurança pública, criminalidade, violência, análise espacial de crimes, justiça juvenil, curso de vida e trajetória criminal, policiamento orientado a problema. Bolsista de Produtividade CNPq (categoria 2).

E-mail: braulio.fas@gmail.com

\section{FREDERICO COUTO MARINHO}

https://orcid.org/O000-0002-1405-3125

Graduado em Ciências Sociais, Mestre e Doutor em Sociologia UFMG/ Université de Lille. Professor do Departamento de Geografia e do Programa de Pós-Graduação em Prevenção da Violência do Departamento de Medicina da UFMG. Pesquisador do Centro de Estudos de Criminalidade e Segurança Pública (CRISP). Membro pesquisador do INCT Espaço Urbano e Gestão da Segurança Pública. Atua principalmente nos seguintes temas: justiça juvenil comparada, prevenção da violência e criminalidade, políticas públicas de segurança, teorias sociológicas do crime.

E-mail: fcfrederico9@gmail.com 


\section{JULIANA MARCONDES PEDROSA DE SOUZA}

https://orcid.org/0000-0001-7801-0098

Possui graduação em Psicologia; Mestrado em Psicologia pela UFRJ; Doutorado em Psicologia pela Puc Minas com pós doutorado em Psioclogia pela UFSJ. Professora do curso de Psicologia do Centro Universitário Metodista Izabela Hendrix e da Faculdade Pitágoras de Venda Nova; Atua principlamente nos seguintes temas: políticas públicas da infancia e juventude; violencia e criminalidade juvenil; sofrimento psíquico na adolescencia.

E-mail: juliana.marcondes@yahoo.com.br

\begin{tabular}{ll} 
Histórico & Submissão: 03/08/2018 \\
& Revisão: 17/03/2019 \\
& Aceite: 12/04/2019 \\
& Concepção: LCPO; JOM; BFAS; FCM; JMPS. \\
& Coleta de dados: LCPO. \\
& Análise de dados: LCPO; JOM; BFAS; FCM; JMPS. \\
& Elaboração do manuscrito: LCPO; JOM; BFAS; FCM; JMPS. \\
& Crítico revisões de conteúdo intelectual importante: LCPO; \\
JOM; BFAS; FCM; JMPS. & Final aprovação do manuscrito: LCPO; JOM; BFAS; FCM; \\
& JMPS. \\
& FAPEMIG - Edital Universal - Processo: APQ-00175-14 \\
& Braulio Figueiredo Alves da Silva - Bolsa de Produtividade PQ \\
Financiamento dos autores & FAPEMIG - Edital Universal - Processo: APQ-02862-17 \\
& Jacqueline de Oliveira Moreira - Bolsa de Produtividade PQ \\
\hline $\begin{array}{l}\text { Consentimento de } \\
\text { uso de imagem }\end{array}$ & $\begin{array}{l}\text { Foi obtido o consentimento escrito dos participantes e/ou do } \\
\text { detentor dos direitos autorais sobre a imagem. }\end{array}$ \\
\hline $\begin{array}{l}\text { Aprovação, ética e } \\
\text { consentimento }\end{array}$ & Não se aplica \\
\hline
\end{tabular}

